\title{
Penis Cancer: About Three (03) Observations at the University Hospital of Bouake
}

\author{
Akassimadou N’Diamoi, Dje Koffi, Avion Kouassi', Aguia Brice, Zouan Freddy, Alloka Venance \\ Urology Department of the University Hospital Center (CHU) of Bouake. Bouaké, Ivory Coast \\ Email: ndiamoi74@gmail.com,Djekoffi1958@gmail.com, *avionkouassi@yahoo.fr, donbricofr@gmail.com, \\ docteurzouan@gmail.com, venancedagotchaka@gmail.com
}

How to cite this paper: N'Diamoi, A., Koffi, D., Kouassi, A., Brice, A., Freddy, Z. and Venance, A. (2020) Penis Cancer: About Three (03) Observations at the University Hospital of Bouake. Open Journal of Urology, 10, 192-200.

https://doi.org/10.4236/oju.2020.106022

Received: March 1, 2020

Accepted: May 25, 2020

Published: May 28, 2020

Copyright (c) 2020 by author(s) and Scientific Research Publishing Inc. This work is licensed under the Creative Commons Attribution International License (CC BY 4.0).

http://creativecommons.org/licenses/by/4.0/

\begin{abstract}
Objective: To report the diagnostic aspects and the therapeutic difficulties of this disease, to contribute to the prevention and screening of this cancer and propose a diagnostic, therapeutic and psychological management of penile cancer of patients at Bouaké University Hospital Center based on a short series of three (03) observations. Patients and Method: Over a period of five years (January 2012 to December 2017), we collected three (03) cases of cancer of the penis. Results: A total of three (03) cases of epidermoidal carcino$\mathrm{ma}$ of the penis were diagnosed. The average age of the patients is [ 52 years], all of them of low socio-economic level. Two $(02)$ patients $(n=2)$ categorically refused surgical treatment (penile amputation) and one (01) patient was lost to follow-up. Two patients are currently deceased. Conclusion: Penile cancer has been an aggressive tumor with a pejorative prognosis, due to the delay of consultation in our underdeveloped countries. Patients consult late but above all refuse any idea of surgical treatment on the penis. The effort to be made is to insist on the prevention and screening of penile precancerous lesions by an adequate training of urban medical staff by a squad of specialists (urologists, oncologists and dermatologists).
\end{abstract}

\section{Keywords}

Penis, Cancer, Penile Amputation, Precancerous Lesions

\section{Introduction}

Cancer of the penis represents all the primary malignant tumors developed at the expense of the penis (foreskin - glans - cavernous corpus).

It is a rare tumor [1] [2], occurring around the 6th decade and its incidence is variable [3]. 
In the West, this tumor represents approximately $0.7 \%$ to $0.8 \%$ of adult male cancers, while in South-East Asia, Africa and Brazil its incidence reaches 17\% [1] [4].

In Côte d'Ivoire its incidence is rare, constituting about $0.3 \%$ of cancers [5]. Infections, particularly HPV (HPV 16) and bad local hygiene are recognized as risk factors, while neonatal circumcision is thought to play a protective role [1] [2].

The most common histological type is epidermoidal carcinoma, which is multifaceted, ulcerative or budding, localized or invasive over the entire penis [1] [3].

Diagnosis is most often suggested by clinical examination.

The therapeutic modalities for penile cancer are multiple and complex and always adapted to the TNM stage (2009) [3], the tumor grade associated with psychotherapy [1] [2].

However, the prognosis remains pejorative because patients consult at an advanced stage and especially refuse any idea of penile amputation [1] [6].

In Côte d'Ivoire, particularly at the University Hospital Center of Bouaké, very little work has been done on penile cancer and its treatment, so we decided to carry out this work whose general objective was to contribute to the prevention of screening, diagnosis and treatment of penile cancer.

\section{Patients and Methods}

Over a period of five years (January 2012 to December 2017), we have collected three (03) cases of penile cancer at the urology department of the University Hospital Center of Bouaké, whose observations are summarized below.

\subsection{Observations}

\subsubsection{Observation 1}

This is a 70-year-old patient, circumcised in childhood, farmer, living in Ferkessédougou, in northern Cote d'Ivoire, married, father of five (05) children, of low socio-economic level who consulted in January 2012, for a lesion of the penis evolving for eight (08) months, swollen and painful afterwards.

According to the patient, the lesion appeared in the form of an oozing wound, associated with local pruritus, neglected by the patient. The evolution was marked by a worsening of the symptomatology preventing sexual intercourse.

Clinical examination revealed an anxious patient with a preserved general condition.

An ulcerous-budding wound of the glans of the penis, about $5 \mathrm{~cm}$ in diameter, with a dirty bottom and irregular contours, bleeding on contact, an erect and painful penis, with induration of the cavernous corpus (Figure 1), the urethral meatus was obstructed. There were no inguinal adenopathies. The somatic examination of the other elements had no particularity. The patient underwent a cystotomy. 


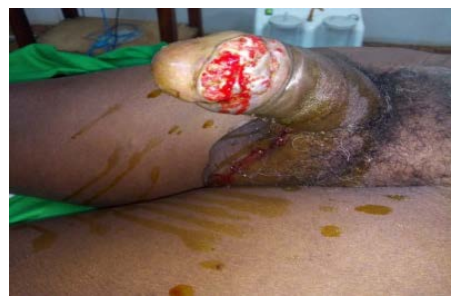

Figure 1. Ulcerous budding wound of the bleeding glans on contact with the erectile penis.

A biopsy and anatomo-pathological examination of the tumor were performed and revealed an advanced epidermoidal carcinoma of the penis (Figure 2).

The penile ultrasound performed objectified an infiltration of cavernous corpora. An antibiotic therapy was instituted and was made of $3 \mathrm{rd}$ generation cephalosporin + metronidazole associated with local antiseptic and analgesic treatments.

The patient was discharged against medical advice and was lost to follow-up.

He came back eight (08) months later in a general state alteration table. We concluded at a terminal stage of penis cancer. The patient benefited from a treatment based on analgesic, blood transfusion and an ulceration bandage. the patient died on August 10, 2012 in a sepsis condition.

\subsubsection{Observation 2}

Mr. N.C., a 44-year-old patient, building technician, residing in Bouaké, uncircumcised, married and father of two (2) children who consulted in February 2014 for penile ulceration and ulcerous-budding inguinal tumefaction evolving since approximately one year and 03 months.

The interrogation of the patient reports the notion of recurrent para phimosis, a sexually transmitted infection (STI) in adulthood.

The beginning of the symptomatology was about 1 year and a half ago with the appearance of an ulcerated swelling, located at the level of the glans, progressively increasing in size, becoming painful later on and interfering with sexual intercourse. Severe dysuria and initially non-fistulized inguinal adenopathies were also noted; all this evolved in a context of apyrexia and a progressive alteration of the general state.

Loco-regional examination revealed an ulcerous-budding wound invading the entire glans, hemorrhagic, deforming it and obstructing the navicular fossa (Figure 3).

In the right and left inguinal region, there was deep ulceration corresponding to fistulized inguinal lymphadenopathy, with irregular, dirty-bottomed margins. The cavernous corpora were indurated (Figure 3).

The patient was hospitalized; a cystostomy was performed.

Examination of the other elements had no particularity.

A bi antibiotic therapy consisting of 3rd generation cephalosporin + metronidazole was instituted with local antiseptic care. 


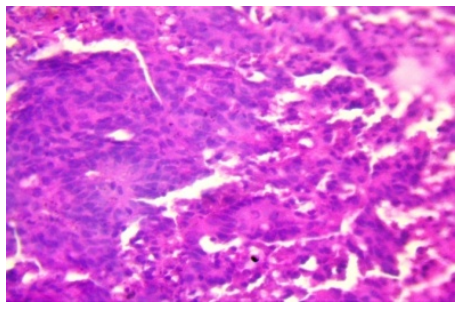

Figure 2. Slightly differentiated epidermoidal carcinoma of the penis: microscopic appearance.

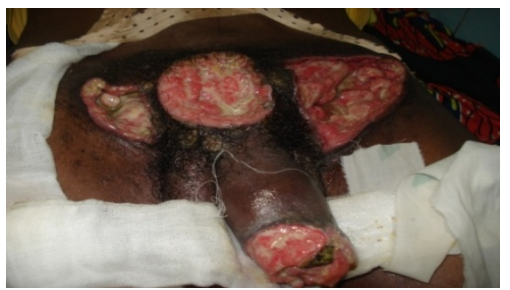

Figure 3. Necrotic ulcerous wound of the glans and fistulized inguinal adenopathies after more than one year of evolution.

A biopsy of the tumor revealed an epidermoidal carcinoma of the penis (Figure 4).

The patient was discharged from hospital against medical advice and died three (03) months later in a severe sepsis.

\subsubsection{Observation 3}

Mr. K.K.D., 62 years old, farmer, residing in Béoumi, circumcised in childhood at the age of five (05) years old, who consulted in 2016 for a hemorrhagic lesion of the ventral face of the penis that had been evolving for approximately ten (10) months.

The beginning of the signs was marked by the progressive appearance of a small shiny tumefaction located on the ventral face of the penis, which will then ulcerate and increase in volume, making sexual intercourse painful. There was no association of dysuria.

The history was unremarkable.

On clinical examination, he was anxious and was in good general condition with colored conjunctiva. Local examination noted an ulcerous-budding lesion located at the base of the penis on its ventral side about $6 \mathrm{~cm}$ in diameter (Figure 5).

It was hemorrhagic on contact with irregular contours; the rest of the penis was flexible. There were no inguinal adenopathies.

Biopsy and anatomo-pathological examination of the lesion revealed an epidermoidal carcinoma of the penis that was slightly differentiated (Figure 6).

A prescribed extension assessment (ultrasound, MRI) could not be performed. Examination of the other elements was normal.

A total amputation of the penis as a treatment has been refused by the patient.

The patient was lost sight of. 


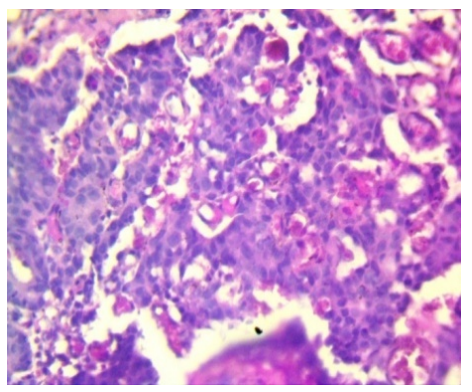

Figure 4. Epidermoidal carcinoma of the penis: microscopic appearance.

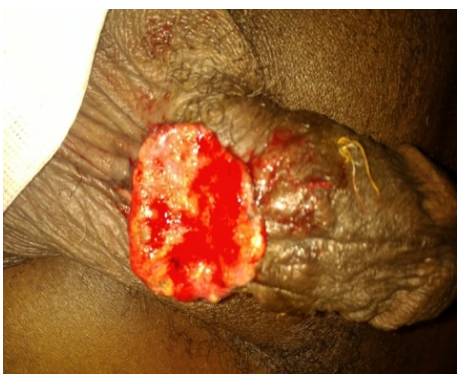

Figure 5. Ulcerous budding wound at the base of the penis bleeding on contact.

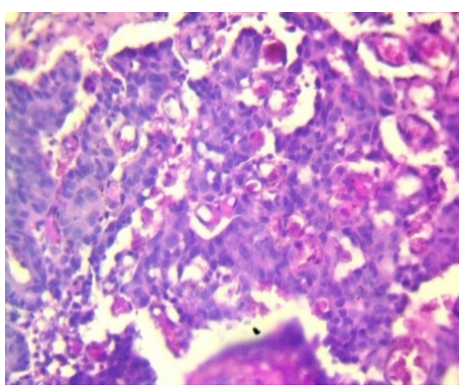

Figure 6. Epidermoidal carcinoma of the penis.

\section{Comments}

\subsection{On the Epidemiological Level}

\subsubsection{Frequency}

Epidemiologically, penile cancer is rare in Cote d'Ivoire [5] (0.3\%); three (03) cases diagnosed in five (05) years at the University Hospital Center of Bouaké.

This rarity is mentioned by Magueye in Senegal with $0.35 \%$ and Nouri in Morocco with six (06) cases in ten (10) years [7] [8].

This could be explained by the practice of ritual circumcision of our populations in the north in particular and in Côte d'Ivoire in general.

The incidence of this condition varies according to geographic location.

It represents $0.7 \%-0.8 \%$ of cancers in Europe, $17 \%$ in South-East Asia and Brazil and is estimated at $0.1 \%$ in Israel [1] [2] [3].

This observation can be explained by the low socio-economic situation of our patients and by the inadequacy of our hospital data. 


\subsubsection{Age}

The mean age at diagnosis in our study is 56 years and is consistent with the literature.

Magueye has an average age of 50 years and Nouri in Morocco 65 years.

If we gather the different series of Nouri, Magueye and our own, we observe that the majority of patients are over 50 years old [6] [9] [10].

This distribution is $70 \%$ of cases after 50 years [1] [6] [9] [10].

\subsubsection{Factor of Risks}

Tumor may occur as a result of chronic inflammation of the glans or a lack of local hygiene [9] [11]. In our study, the search for precancerous lesions was unsuccessful due to the late consultation [9] [11].

\subsubsection{Anatomo-Pathology}

The most frequent histological form is epidermoidal carcinoma in $95 \%$ of cases [1] [2] [6] [7] [12].

All our patients had squamous cell carcinoma of the penis. These findings comply with the literature review [1] [2] [3] [6] [7].

Regarding the localization, the lesion was located on the glans in three patients and on the ventral side, at the base of the penis in one patient [6].

\subsection{Diagnostic}

\subsubsection{Clinic}

It is an ulcerous budding tumor whose circumstances of discovery are represented by a painless lesion with a type of burn, pruritus, bleeding on contact with an increase in the volume of the glans [1] [2] [6] [7] [12].

Sometimes phimosis or clinical signs (acute urine retention, dysuria) may appear, which are rare.

The diagnosis is primarily clinical based on palpation of the penis, tumor and areas of ganglion in search of inguinal adenopathies.

In our series, the diagnosis of cancer was confirmed by examination of the penis and ganglion areas, which revealed the tumor located at the glans in two (02) patients and at the base of the penis in one (01) patient.

The size ranged from $5 \mathrm{~cm}$ to $6 \mathrm{~cm}$ in diameter in all patients.

The location of the lesions was at the level of the glans and the balano-preputial groove in three (03) patients. In the literature review, the tumor preferentially affected the glans [1] [2] [3] [4] [6].

The cavernous corpora were invaded in two (02) of our patients out of two (02) (50\%) and one (01) patient had a lesion infiltrating the urethra.

Nourri and $\mathrm{Al}$ noted tumor lesions of the penis all localized at the level of the glans and the preputial balano groove with two patients, with tumors infiltrating the urethra [8].

In our series, two patients had presented a tumor infiltrating both the cavernous corpus and the urethra causing urine retention. Palpation of the inguin- 
al regions revealed fistulized inguinal adenopathies in one patient. These inguinal ganglions are most often present in advanced tumors of the penis [1] [2] [6].

In Teck-Weik and Nourri, half of the patients presented a ganglionate location [8] [10] [11].

\subsubsection{Paraclinical}

Tumor biopsy is necessary in case of doubtful diagnosis and will reveal the histological type of the penile tumor [1].

In our series, the different biopsies performed on the tumors and the anatomo-pathological examination reported $100 \%$ of epidermoidal carcinomas, in agreement with the results in the literature. Indeed, epidermoidal carcinoma appears by far as the most frequent histological type [1] [2] [3] [4] on the radiologic level, the ultrasound and penile MRI can help in the diagnosis but above all can confirm cavernous and ganglionate extension [1].

Our patients were not able to benefit from additional examinations because of their low socio-economic conditions but also due to the insufficiency of the technical facilities.

The discovery of the PET scanner is a scientific revolution in the diagnosis of penile tumors [1] [6].

In our series, local extension was sought by clinical examination of the penis (palpation of the penis) sometimes supplemented by penile ultrasound.

None of the patients was able to perform the penile MRI, which is the best test for extension assessment [1].

\subsection{Therapeutic}

The management of penile tumors is complex in our regions.

Surgical treatment is based on partial or total amputation of the penis, which may be associated with a removal of ganglion [1] [6].

Surgery should be conservative at most as long as the lesion allows [1] [6] [10].

Penile amputation is the removal of the tumor with a safety margin but leaving if possible a sufficient part of the penis $(>3 \mathrm{~cm})$ to preserve the function of the penis. The major complication is mesal stenosis (7\% - 10\%) [1] [2]. 3 out of 4 patients refused penile amputation in our study.

A perineal urethrostomy should be performed if the penis is completely amputated.

In our series two patients were lost to follow-up after refusing surgical treatment; one patient died with severe sepsis.

Refusal of penile amputation is very common among our patients in sub Saharan Africa.

In our short series of three patients, two refused amputation of the penis due to ethical and customary issues. Other therapeutic modalities exist such as radiotherapy and laser therapy [1] [6]. 


\subsection{Psychological, Evolutionary and Prognostic Plan}

The psychological profile of our patients was marked by anxiety and distress, as Magueye notes [7] occurring because of the location of this tumor on the intimate parts [7].

The evolution was marked by the probable extension of the tumor and death. Three patients died and one patient was lost to follow-up comparable to the high death rate if diagnosed late as Magueye mentioned it [1].

The prognosis was fraught with complications and was pejorative. [1] [6] [7].

\section{Conclusions}

In our work, malignant tumors of the penis were exceptional, rare and their treatments are complex in Cote d'Ivoire.

This tumor occurs at an average age of about 55 years. Favoring factors are neglected by our patients and diagnosis is most often late at an advanced stage in our African countries.

Epidermoidal carcinoma is the most common and surgical treatment based on partial or total amputation of the penis, is most often refused by patients, which puts a heavy burden on the prognosis of this rare and complex cancer.

A multidisciplinary team of urologists, cancer specialists and dermatologists should be formed to assist the formation of medical staff, screening, prevention and treatment of precancerous lesions of the penis.

\section{Conflicts of Interest}

The authors declare no conflicts of interest regarding the publication of this paper.

\section{References}

[1] Rigaud, J., Avances, C., Camparo, P., Durand, X., Fledron, A., Murez, T., Sebe, P., Coloby, P., Culine, S., Ibora, F., Mollet, N. and Soulié, M. (2013) CCAFU Recommandations onco urologie 2013 du CCAFU: Tumeurs malignes du pénis. Progrès en Urologie, 23, 135-144. https://doi.org/10.1016/S1166-7087(13)70051-4

[2] Mottet, N. (2003) Epidémiologie du cancer de pénis [Epidemiology of Penile Cancer]. Progrès en Urologie, 13, 1237.

[3] Rigaud, J., Avances, C., Camparo, P., Culine, S., Durand, X., Iborra, F., et al. (2010) Recommandations en Once-urologie 2010: Tumeurs malignes du pénis. Progrès en Urologie, 20, S279-S289. https://doi.org/10.1016/S1166-7087(10)70044-0

[4] Hakenberg, O.W., Compérat, E., Minhas, S., Necchi, A., Protzel, C. and Watkin, N. (2014) EAU Guidelines on Penile Cancer.

[5] Echimane, et al. (1993) Cancer Incidence in Africa 1993.

[6] Cornu, J.N., Compérat, E., Renard-Penna, R., Misrai, V., Bitker, M.O., Hertig, A., Chartier, E., Kaster, R.F. and Roupret, M. (2007) Prise en charge carcinologique des cancers du pénis. Expérience d'un centre. Progrès en urologie, 17, 1347-1350. https://doi.org/10.1016/S1166-7087(07)78575-5

[7] Gueye, S.M., Diagne, B.A., Ba, M., Sylla, C. and Mensah., A. (1992) Cancer de la verge: Aspects épidémiologiques et problèmes thérapeutiques au Sénégal. Médecine 
d Afrique Noire, 39, 582-584.

[8] Nourri, A., El Akarni, E., El Yacoubi, S., Kamouri, T., El Kahder, K., et al. (2012) Cancer du pénis: A propos de 06 cas et revue de la littérature. African Journal of Urology, 18, 66-70. https://doi.org/10.1016/j.afju.2012.04.014

[9] Fair, W.R., Fuck, Z.Y. and Scher, H.I. (1993) Cancer of the Urethra and Penis. In: De Vita, V.T., Helmen, S. and Rosemberg, S.A., Eds., Cancer. Principals and Practices of Oncology, Lippincott Company, Philadelphia, PA, 1114-1125.

[10] Sow, M., Nkegoum, B., AmaMoor, V.J. and Decremoux Xavier Sastre-Garau, P. (2006) Les tumeurs malignes du pénis au Cameroun: Aspects épidémiologiques cliniques, anapathomo pathologiques et thérapeutique. Annales de Pathologie, 26, 299-301. https://doi.org/10.1016/S0242-6498(06)70730-1

[11] Ficarra, V., Mofferdin, A., D’amico, A., Zanon, G., Schiavone, D., Malossini, G., et al. (1999) Comparaison de la qualité de vie des patients traites pour cancer épidermoïde de la verge par chirurgie ou radiothérapie. Progrès en Urologie, 9, 715-720.

[12] Bastide, C. (2003) Prévention et dépistage du cancer du pénis. Progrès en Urologie, 13, 1238-1242. 